\title{
CURVE-BASED E-LEARNING EFFICIENCY GRADING
}

This study proposes a new method for measuring e-learning efficiency. Efficiency assessment has been fairly contradictory in traditional educational systems. After reviewing the assessment limits of traditional educational systems, the authors used e-learning characteristics to propose a new assessment method based on the distribution of the educational process parameters (and not those of the students' results). They also assign specific evaluation criteria and key indicators that are linked to the parameters of the e-learning process. The essence of the new method is that the efficiency of individual e-learning courses can be evaluated based on standard distribution features on their own and can be compared with similar courses as well.

\section{Keywords: E-learning, efficiency, standard distribution, key figures}

\begin{abstract}
"When you can measure what you are speaking about, and express it in numbers, you know something about it; but when you cannot express it in numbers, your knowledge is of a meager and unsatisfactory kind; it may be the beginning of knowledge, but you have scarcely, in your thoughts, advanced to the stage of science." (William Thomson, Lecture on "Electrical Units of Measurement" (3 May 1883), published in Popular Lectures Vol. I, p. 73.)
\end{abstract}

$\mathrm{M}$ anagement science shares the views above worded by William Thomson ${ }^{1}$ regarding leadership, organizational, and management processes. In the business areas created by new technologies, widely accepted measurement systems eventually emerge. E-learning has been used for more than ten years, but it is still a new and highly evolving technology and phenomenon. Researchers are comparing the outcomes of e-learning and traditional education forms, and some forms (namely skill-based courses) outperform traditional education (Callister - Roberts - Love, 2016).

No consolidated and consistent measurement system has been developed in the emerging field of e-learning. Other studies examining the method of student evaluation of teaching efficiency (SETE) have emphasized that emerging online educational methods necessitate the revision of earlier assessment methods (Galbraith - Merrill Kline, 2012). One of the goals of this study is to eliminate this gap by offering a measurement-rating framework. E-learning provides an opportunity for a unique education measurement system.

We explored the basic requirements of modern performance measurement systems. Based on the identified specificities of e-learning, we propose a measurement-rating framework that exploits the relevant opportunities. The method is based on the statistical distribution of the results of an educational process and not those of the students' results, for which we also assign specific evaluation

1 Often referred to simply as Lord Kelvin criteria and key indicators. The new approach can also be used for comparison with similar courses in no specific environment, thus it can be applied to including but not limited to secondary education, higher education or in the corporate sector.

\section{Differences between e-learning and traditional learning}

Guri-Rosenblit and Gros (2011) and Sangrà, Vlachopoulos, and Cabrera (2012) offer a perfect discussion of the basics of e-learning. But instead of providing a long overview, we present the differences from traditional attendance-based (classroom) learning as an important starting point in identifying the shortcomings and possibilities in the related measurements. Based on our findings, there are seven main ways in which e-learning is different from face-to-face learning:

1. Time-independency. In traditional courses, students are forced to acquire knowledge at a given time and usually regularly. In case of e-learning, students learn when it is most suitable for them.

a. Ability to repeat. In traditional courses all students have to pick up and adjust to the teacher's pace. In the case of e-learning, the contents may be consumed at one's own pace, they can also be reviewed at an unlimited number of times.

b. Learning pace. As a direct consequence of flexible timing, in case of e-learning students do not have to spend the same amount of time studying a given section.

2. Location-independency. In the case of e-learning, mobility allows students to choose the place of learning, whether in a public area, park, commuter train or the nursery of a house.

3. Continuity. In case of an attendance-based learning, the personal presence of the teacher provides an opportunity for students to ask questions right 
away and clarify unclear points quickly. In case of e-learning, this opportunity is typically provided in an asynchronous way (e.g. via electronic messages).

4. Teacher-independency. In a classroom, the students usually do not have any options, and they have to accept the teacher in regard to his appearance and lecturing style. E-learning offers an opportunity for creating more teacher-independent content.

5. Learning paths. In a classroom, there might be students who are partly familiar with the content and for whom half of the information conveyed is not new. This means unnecessary repetition. E-learning provides a possibility for the students to choose the content elements they want to learn and to prove the knowledge they obtained earlier.

6. Visualisation. Presentations (mostly PPTs) created for a classroom environment are for guiding the teacher rather than for aiding student understanding, whereas all visual or audio elements in e-learning content serve the student's progress better.

7. Gamification. The classroom environment provides only limited opportunities for competition by solving smaller tasks or distributing good points. However, e-learning ensures a much more colorful toolkit for making learning a game.

In order to have an overview of the advantages' complexity, we created a classification on the findings above, and sorted them into three overlapping categories. Some of the advantages has the ability to make learning adaptable and repeatable for the learners. Others create a more convenient and flexible environment in the learning process. And there are also some advantages which are capable of making learning easier and faster. It is worth mentioning other classifications grouping by high accessibility, flexibility, time and cost/investment benefits (Nesterowicz et al., 2016). (see Figure 1.)

Figure 1.

How e-learning is different from traditional learning

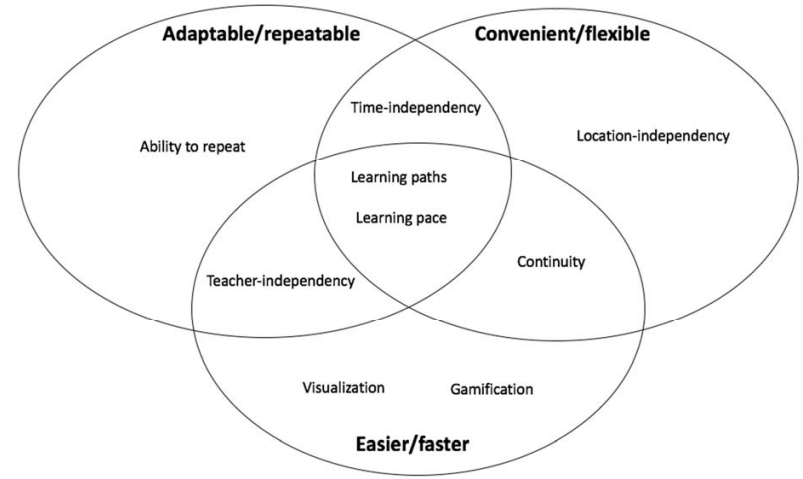

The criteria system above reflects the differences between traditional classroom learning and e-learning very well. In short, students have to obtain new knowledge among conditions in a classroom environment that are forced on them from many aspects and with the teacher being an important element of education. By contrast, e-learning provides freedom for the student to determine the place, time, pace, and style that are most comfortable or suitable for them, and the teacher's personality is not necessarily reflected directly in the e-learning content.

\section{Why new measurement methods are necessary in case of e-learning?}

The primary metrics of traditional education mainly evaluates the student and its obtained grades or asses the teacher himself (e.g., SETE, which will be discussed) and the latter obviously cannot be applied in the case of e-learning. This is why the traditional measurement system needs to be revised, and an improved system of metrics must be created, which should emphasize knowledge transfer and make it easy to compare e-learning materials with different styles, contents, and topics.

The new measurement system is essential and viable because technology enables it, new areas (not only satisfaction or grades) can be measured unbiasedly without evaluator qualification error. Improving the measurement of traditional teaching efficiency is very constrained, it is difficult to adopt them in connection to e-learning thus with the new metrics comparison with traditional learnings is more convenient. Last but not least the new metrics can be used to fine tune or restructure teaching materials in course design and a continuous improving dialogue can be sustained by evaluating the new indicators.

\section{What do we expect from a good measurement system?}

In addition to the educational evaluation requirements discussed elsewhere in this article (Taylor, 2010), there is a list of key principles of correct evaluation for the assessment of performance management systems:

- representative faithfulness: correlation between the measurement and the phenomenon to be measured,

- comparability (via benchmarks) corresponding to the evaluation criteria,

- correlation with other measurement metrics: indices that are compatible with the rest of the areas of business performance measurement,

- clarity: being relatively easy to understand and work with,

- reliability: users can rely on the figures,

- verifiability: a consensus value created between several independent measurements (and people carrying out the measurements); for example, proposal: probability-weighted average of experts (systems).

The further knowledge expected from indices (e.g., Seang, 2003) is:

- planning, controlling, and the support of evaluating systems,

- communicability (especially for internal use), 
- optimization of resources,

- motivation: performance may improve after defining goals that can be individually performed.

Holsapple, Clyde, and Lee-Post (2006) approach the success of the introduction of e-learning from the perspective of information technology systems. Importantly, in the case of information systems, not only individual effects but also effects on the organization need to be considered (DeLone - McLean, 1992). For brevity, this article deals with only measurements relating to the individual. (see Figure 2.)

Figure 2 .

The original information system success model created by DeLone et al. (1992)

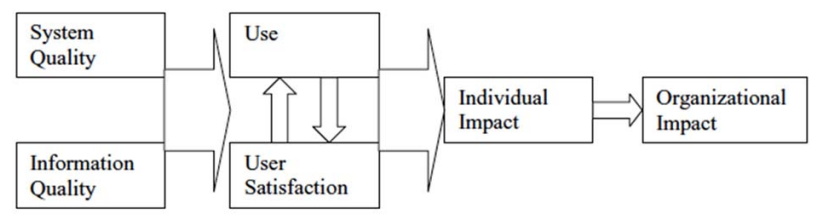

\section{Current education-measurement systems and their criticism}

In everyday life, the terms "effective" and "efficient" are often not used clearly. This is why it is important to clarify the differences between the terms in regard to knowledge transfer and learning. The difference between these terms is obvious in management sciences:

- effective (adj.): adequate to accomplish a purpose; producing the intended or expected result,

- efficient (adj.): performing or functioning in the best possible manner with the least waste of time and effort (Nelson, 2018, p. 356.).

In other words, being effective is about "doing the right things," while being efficient is about "doing things right." In regard to teaching, effectiveness refers to the transfer of knowledge as a result, while efficiency refers to the rate of the results achieved and the inputs. Efficiency is also referred as productivity, namely maximizing the quantity of output (number of student and their achievements) while minimizing the use of inputs (Vilaseca - Castillo, 2008).

It is generally acknowledged that e-learning can be a lucrative investment by replacing classroom courses, but in this article, we focus on the aspects of knowledge transfer efficiency (Strother, 2002; Wild - Griggs - Downing, 2002; Vilaseca - Castillo, 2008).

Consequently, a metric system for the efficiency of knowledge transfer needs to be created in the context of the mentioned conditions, of which the quality is rather significant as well. The measurement results could define the ranking of educational institutions or the remuneration of teachers.

According to Tyler (2010), four major criteria must be met when defining a set metric system:
- generalization: the teaching (or teacher) must be measured not once but several times to make general conclusions,

- evaluation: metrics and key figures must be timeless and consistent so that teachers and education can be compared objectively in both time and space, regardless of the topic of education,

- extrapolation: it is important to have a correlation between the metrics and the quality of the education, which means that it must be ensured that the students' good results and performance are achieved thanks to the teaching method and the teacher,

- implication: the created methodology must be applied as a suitable device, whether in the case of creating a ranking of institutions or in the comparison of people.

Current methodologies for the measurement of the efficiency of knowledge transfer are not satisfactory according to Creemers and Kyriakides (2006) either. They point out similar results from two studies that were written independently of each other. Colema, Campbell, Hobson, McParttland, Mood, Weinfield, and York (1966) and Jencks, Smith, Ackland, Bane, Cohen, Grintlis, Heynes, and Michelson (1972) both filter out the students' background conditions (individual skills, family circumstances) in the samples examined, which resulted in the variance of the teaching factors remaining very low. This means that different teachers and teaching methods have more or less the same efficiency in the case of students with similar backgrounds. Heyneman (2005) also comes to the conclusion that social status strongly determines student performance, however he also examines whether the purpose of public schools are making the performance gap disappear or fostering social cohesion.

Hanushek and Luque (2002) come to the conclusion that student performance is has a connection on how efficient is the use of resources, but comparing both developed and poor countries shows that these problems are independent from the level of resources. Woessmann (2004) points out that in developed countries (such as the U.S. or Western Europe) family-background characteristics have strong effects on student performance. The Tennessee Value-Added Assessment System (TVAAS) is also worth looking at, as it is a good measurement system for teaching effectiveness which controls implicitly for socioeconomic status and background. There are also some experiments and research modifying the TVAAS (e.g. Sanders and Wright (2004)).

One of the most popular measurement methods of teaching efficiency is student evaluation (SETE). A study by Galbraith et al. (2012) shows a counterexample for the relations between students' results and the teacher's evaluation not being linear, supporting the claim with various mathematical methods. Students achieving the best results tend to evaluate the teachers as having medium quality, while students with weak performance prefer extremes: they evaluate the teacher either with very good or very bad scores. When examining the SETE method, the authors 
also state that new teaching methods such as online courses and hybrid courses have emerged, which makes revision of the SETE method necessary (Galbraith et al., 2012). (see Figure 3)

Figure 3.

Results of Galbraith et al. (2012)

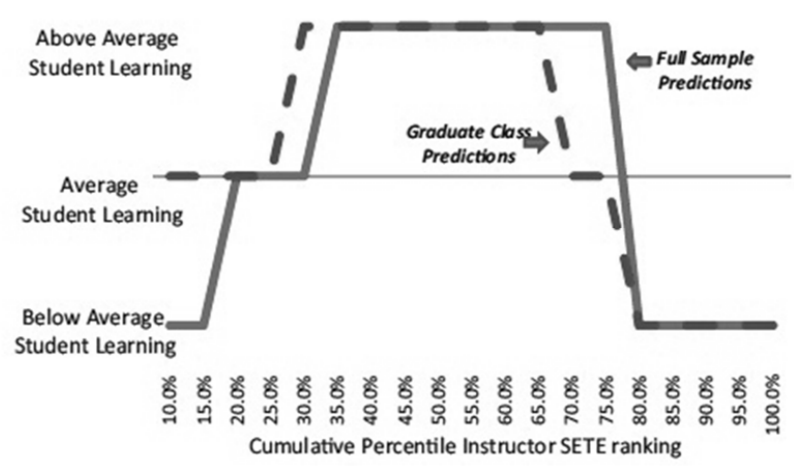

At the same time, other authors emphasize the fact that the knowledge transfer is strongly dominated by student satisfaction (Eom - Sean - Wen - Ashill, 2006). Ten years later, the model was refined somewhat, and new explanatory factors of student satisfaction were identified, such as course design, instructor, and dialogue (Eom - Sean - Ashill, 2016). Student satisfaction is a defining factor, which is well evidenced by an analysis conducted on a rather large empirical sample, which emphasizes the importance of individual learner characteristics. This means that if these characteristics are filtered out, the remaining learning experience itself is similar for everyone ( $\mathrm{Li}-\mathrm{Nai}$ - Marsh - Bart Rienties, 2016). This agrees with Creemers and Kyriakides (2006), according to whom the observable standard deviation disappears after filtering out students' backgrounds and grades.

Emery, Kramer, and Tian (2003) also criticize the SETE method based on the following groupings:

- Popularity and personality contests. Teachers' evaluations are often influenced more by popularity than teaching efficiency. Students' subjective evaluations are affected by simple factors, such as whether the teacher brings food into the classroom for the students.

- Student achievement. Although students' achievements are perhaps the clearest and most indirect feedback about a teacher's efficiency, studies supported by examples show the opposite; that is, the teachers' evaluation is reflected in the students' achievement to a minimum extent only.

- Situational factors and validity. A relation can be seen between the courses and the evaluations related to them. For example, the authors compare art and science subjects, and there is a difference between obligatory and optional subjects as well.

- User error. Incorrect interpretation of the results of SETE or their analysis with an incorrect statistical method might lead to serious problems as well. Since sample sizes are usually small (courses with fewer than 30 students), the possibility of statistical error is much higher.

- Evaluator qualification error and defamation. The last aspect criticizes the students themselves. Students are generally said to not be able to think critically. Evaluators are not pre-filtered in any way, which would entitle them to evaluate the teachers, so intentional defamation can easily occur.

All in all, a large part of the literature criticizes the current methods for measuring traditional teaching efficiency. However, studies attempt to define principles and give recommendations for the improvement of the current methods. Berk (2012) makes twelve recommendations for improving the measurement of teaching efficiency. He lists twelve possible sources from which proof can be obtained regarding a teacher's evaluation:

1. student ratings: the students evaluate the teachers according to a given scale,

2. peer ratings: the teachers evaluate each other on a given scale,

3. self-evaluation: the teacher evaluates himself or herself on a given scale,

4. videos: the teaching is recorded on video and evaluated (by the teacher himself/herself or another teacher/expert),

5. student interviews: students are "questioned" not individually but collectively,

6. alumni ratings: the teachers are evaluated by alumni,

7. employer ratings: the students' employers evaluate the students (and thus the teachers indirectly),

8. administrator ratings: administrators of the educational institution evaluate the teachers,

9. teaching scholarship: examining the scholarships awarded to the teachers,

10. teaching awards: examining the prizes and acknowledgements awarded to the teachers,

11. learning outcome measures via the students' achievements,

12. teaching portfolios, which collect the above via several factors.

Besides the information sources, the list also contains the types of indicators (rating scales, reviews, etc.) and specifies the person it is from, the person who can use the information, and what kind of decision can be made with it. (see Table 1.)

Berk's proposals are overly teacher-centered rather than teaching-centered, which means that it is difficult to adopt them in connection to e-learning. Points 1, 6 and 11, however, can also be interpreted in the context of e-learning. Certain teaching features have such a great impact that e-learning can only be a superior mode of instruction if the students specifically like to study in a visual and writing/reading style and receive several kinds of feedback from teachers. 
Table 1.

Summary of Berk's (2012) proposals

\begin{tabular}{|c|c|c|c|c|}
\hline$\#$ & Source of Evidence & Type of Measure(s) & Who Provides Evidence & Who Uses Evidence \\
\hline 1 & Student Ratings & Rating Scale & Students & Instructors/Administrators \\
\hline 2 & Peer Ratings & Rating Scale & Peers & Instructors \\
\hline 3 & Self-Evaluation & Rating Scale & Instructors & Instructors/Administrators \\
\hline 4 & Videos & Rating Scale & Instructors/Peers & Instructors/Peers \\
\hline 5 & Student Interviews & Questionnaires & Students & Instructors/Administrators \\
\hline 6 & Alumni Ratings & Rating Scale & Graduates & Instructors/Administrators \\
\hline 7 & Employer Ratings & Rating Scale & Graduate's Employers & Instructors/Administrators \\
\hline 8 & Administrator Ratings & Rating Scale & Administrators & Administrators \\
\hline 10 & Teaching Scholarship & Judgmental Review & Instructors & Administrators \\
\hline 11 & Teaching Awards & Judgmental Review & Instructors & Faculty Committees/ \\
\hline 12 & Learning Outcomes & Tests, Projects, Simulations & Students & Instructors/Curriculum \\
Committees
\end{tabular}

We reckon that the current education-measurement systems are neither effective nor efficient because they only and mainly evaluates the student and its obtained grades or asses the teacher himself and a continuous measurement of the latter proves to be time consuming and expensive.

We also reckon that several above mentioned criteria of a good measurement system are not met in traditional education-measurement systems, for example extrapolation and implications just to name a few. Generally speaking the traditional metrics does not properly reflect to the teaching method and knowledge transfer.

Undoubtedly, the students' learning outcome (in other words, the gained competencies) would have to be an important benchmark, but this cannot always be measured well for the following reasons:

1. exams and other grades do not necessarily correlate with actual knowledge,

2. there is no opportunity for actually measuring knowledge and competence during or after the learning process, it is too costly, or it requires too many resources,

3. no knowledge or no exact knowledge is available regarding the students' competence or their input state preceding the learning,

4. the characteristics of the teaching process (e.g., the teacher's personality, teaching intensity, methods used) cannot necessarily be identified or linked to the measured person,

5. performance can greatly depend on current conditions of the student (state of mind, mood, etc.), which can only be filtered out through several measurements, but the opportunities for this are limited.

The somewhat opposing relationship between the teacher's "goodness" and learning outcome mentioned by Galbraith et al. (2012) supports that it is worthwhile and necessary to measure knowledge transfer, even if it is the teacher's performance that is being measured. Based on the above, it is necessary for the assessment of the teaching system itself to make indirect conclusions regarding the quality of knowledge transfer and for the sake of assessing the teaching process.

\section{The measurement features of e-learning}

This section will explain the necessity of a different and improved measurement system for e-learning knowledge transfer. Then we will elaborate on how teaching could be referred to as a service, and how this influences the creation of the improved measurement system. Finally we will point out the change in competence creation in e-learning.

\section{Why should e-learning be measured differently?}

The issue of heterogeneity is solved in e-learning. As Unified Service Theory (discussed in the next section) states, the goodness of the process and that of the service cannot be separated from each other (e.g., the quality during the performance determines the quality of the end-product, and there is no final inspection or possibility of a recall). However, e-learning makes teaching repetitive. E-learning affects the two basic approaches of knowledge management: personalization and codification. In personalization, knowledge is rather tied to the teacher who shares it, thus the transfer could vary a lot not only by teachers but also by the mood of the teacher. In codification, knowledge is codified and shared in a standard way, thus it can be transferred over and over again at the same quality level.

E-learning makes a kind of codification possible instead of personalization knowledge management, which undoubtedly reduces the user's vulnerability.

By the nature of e-learning systems, the teacher's personality is less significant. The teacher's personality and his technique for knowledge transfer cannot be disregarded in connection to the creation, editing, and presentation of the content, but due to the recording and presentation of 
the content, the selection and inclusion of the teacher is less accidental, since the final content can be edited with the best teachers and their best moments.

\section{Teaching as a service}

Since teaching is some kind of a service, the Unified Services Theory (Sampson - Froehle, 2006) can be applied. Unified Service Theory (UST) is a fundamental model which incorporates customer's reaction, feedback, etc. as production inputs. Education belongs to one of the main service areas according to UST (Sampson, 2001). The theory names ,mind" the input from the customer. The customer feedback part of the model is a very relevant and important in teaching value process too. We use UST as a starting point to set up the measuring framework for e-learning processes because the goodness of the process and that of the service cannot be separated from each other in education. (see Figure 4.)

Figure 4.

Fundamental model of service business operations (Sampson, 2001)

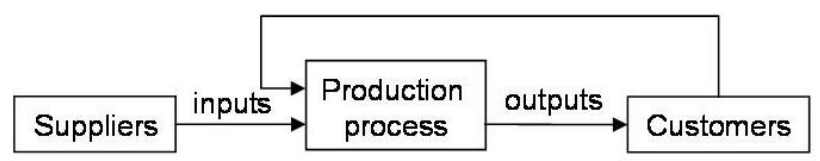

Besides the "mind" mentioned by Sampson as customer feedback during education, the following factors also need to be considered:

- Grade.

- Time spent in the course: if a student is there for a long period of time, she either understands it slowly, or either enjoys it very much.

- Average time between returning to the course: if a student rarely returns, the student does not enjoy the e-learning material or is not motivated enough to return more frequently. Although we should consider this carefully, because the reason of the rare return could be that the student doesn't need to return to the course.

- Number of breaks in the course (how many returns are necessary to complete the entire course): if a student takes many breaks, then the breakdown of the syllabus should be considered to be changed, given that not only one but the majority of students take many breaks.

- Utilization frequency of complementary educational elements (explanatory additions, list of lists, notions, etc.): if elements are used frequently, it is good; if they are not, then they are useless. However, the core syllabus could be shortened and would thus require little explanation.

- Number of questions asked by the students: if there are many questions, the material is probably not understandable.
- Time allocated for the exam (in proportion to the total amount of time permitted as a percentage): if the time is low, the exam is easy, or if there is much time, there is also feedback.

The Figure 5. summarizes the information above. This classic figure should also contain the grading, interactivity, questions, everything we refer to below, and the statistical evaluation mode. We once again refer to these factors at the end of the article in the key figure section that we recommend.

Figure 5.

Extended model of service business operations

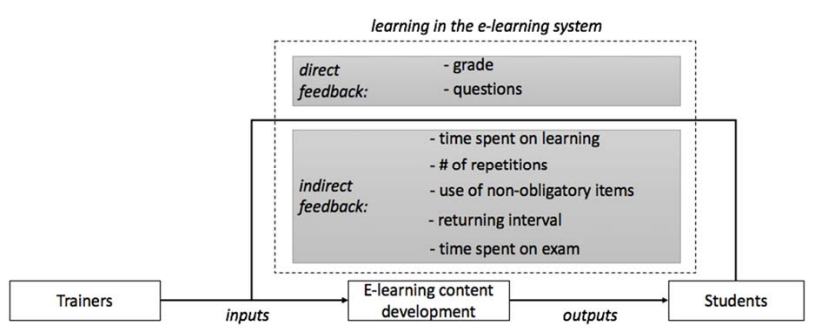

\section{The connection between the measurement areas}

In the case of traditional attendance-based learning, the delivery of knowledge is influenced directly by two factors: the teacher has a direct impact on the students since he or she is delivering knowledge during the training and directly participates in formulating the learning competence. In addition, the educational system has a direct impact on the formulation of competence since it determines teaching and knowledge evaluation regarding "where," "when," "what circumstances," and "what to re-examine." (see Figure 6.)

Figure 6.

Change in competence creation in e-learning

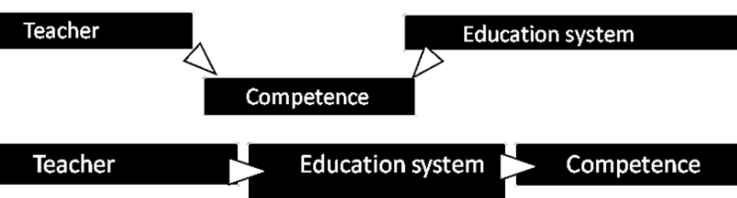

However, in the case of pure e-learning, the student does not interact with a teacher directly. The teacher assists in forming the educational system and contributes to it. The teacher provides the professional content, which is incorporated into the e-learning system during the syllabus development, but does not set the learning pace. The teacher's personal and educational features are not reflected directly in the competence formulated. This means that eliminating the teacher's direct connection should affect the metrics as well. 


\section{A recommended measurement system for e-learning}

This section introduces a measurement system for e-learning courses. We have already defined the characteristics and requirements of a good measurement system earlier, and now we propose the following system of metrics. For the evaluation of e-learning, we divided the measurement possibilities into the following sets of factors.

Areas of measurement:

- the teaching material itself (curriculum),

- the learning management system; that is, the quality of the supporting processes (administration, etc.),

- the transfer of the teaching material.

In this article, we focus on the transfer of teaching material, which can further be divided into the following areas:

- the teacher's rating,

- the measurement of the obtained knowledge and competence,

- the process of teaching (knowledge transfer).

These three factors cannot always be separated from each other, and certain evaluations (e.g., "the teaching was effective") may include all three. In spite of this, it is important to separate them since we cannot measure beyond SETE or without it in a direct way and because of the mentioned difficulties of evaluation.

Our basic approach is that descriptive statistical key figures may be useful for making indirect conclusions in e-learning due to the large number of the same teachings that can be viewed as homogeneous, and not the direct or absolute values. We propose the use of different key figures of volatility and standard deviation to make deductions regarding the goodness of the process by creating divergence.

Repeating the same course may improve the goodness of the deviation creation compared to the general population due to accumulated values of historical data. To gain an idea about the standard deviation, the type of distribution needs to be clarified. The distribution of the teaching performance (efficiency in this case) is typically normal. The reason for this can be found in the following: the distribution of grades is determined by (1) the performance of the students and (2) the grading system.

The student performance is normally distributed. The question is: should the teacher's system distribute grades normally? If student performance is normally distributed, a standard distribution is the outcome of many small variations in inputs that are added up. Student performance depends on many independent factors, such as preparation, education, timing, intelligence, and other circumstances on the day of testing. Several of the mentioned factors are normally distributed by nature. However, according to the central limit theorem, when independent, random variables are added, their sum tends approaches a standard distribution (a Gaussian distribution or bell curve), even if the original variables themselves are not normally distributed. Besides grading on a curve, which automatically ends up in a bell curve, a consistent or absolute grading system will still lead to a standard distribution because another normally distributed factor is added to the system.

Apart from the above, a standard distribution is very important in teaching. Grading on a curve (also referred to as curved grading, bell curving, or using grading curves) is a method of assigning grades designed to yield a Gaussian distribution curve among the students in a class. If we can assume a standard distribution, then there is a question of why it is worth using for evaluation purposes. Firstly, the shape of the standard distribution can be changed to a certain extent, and therefore, the efficiency of knowledge transfer can be improved. Kronholz's (2012) article is a good example, which examined the issue through the popular Khan Academy. According to the author, a Gaussian distribution can be shifted to the right.

Our assumption of normality seems to be a possible basis for a unique measurement system for e-learning. We suggest applying this theory to the mentioned goodness of the teaching process itself, and not simply final grades. Namely, any deviation from a "standard" distribution correlates with achievements and efficiency of the teaching system; that is, the parameters of the e-learning process and their numerous application cases that can be recorded relatively simply provide the possibility of comparative analyses.

The deviation from the standard distribution as a measurement system satisfies the measurement requirements listed above for the following reasons:

- every participant and course can be evaluated through it, and as such, it is representative,

- because of the obtained data, it is comparable in terms of both time and various courses,

- the parameters of the educational process are clear and communicable for both teachers and students,

- they are reliable and verifiable since they are set automatically without any subsequent manipulations or complicated activities for establishing key figures,

- the creation of the key figures does not require any significant efforts; the process parameters simply need to be recorded,

- objectives can be assigned to the key figures (planning and motivation criteria) and can be monitored on a continuous basis.

The normal bell-shaped curve describes the distribution of randomly occurring events when nothing intervenes. Teaching is an intervention and a purposeful and intentional act. We engage in teaching to attain a specific result — that is, to have all students (or nearly all) learn the things we set out to teach. If the distribution of student learning after teaching resembles a normal bell-shaped curve, that, too, shows the degree to which our intervention has failed. It has made no difference (Guskey, 2011).

The fact that a course's educational process follows a normal distribution gives us an opportunity to measure edu- 
cational effectiveness. The basis of our suggested method is that we can record, measure, and quantify the activity and participation of students in e-learning courses. As there are many students in a course, these records result in unique distributions. If a given indicator's distribution does not follow a normal distribution (and is thus distorted somehow), then it has consequences in terms of the goodness of the educational process. Therefore, the results of a simple normality test and distribution analysis could represent the goodness of an e-learning course. Furthermore, if the given course has been repeated multiple times, then the indicators could be compared to each other within the base population.

\section{Specific indices}

As mentioned, the topics of the subject and the evaluation of the teaching material exceed the scope of this article. As an example, we mention that usefulness belongs here as the most important concept, just like the question of whether conceptual or procedural knowledge (internalized, actively used knowledge) has been successfully created. This article does not examine the learning management system, which is the quality of the supporting processes (administration, etc.). At the same time, due to the methodological similarity, it is worth mentioning that because of the normality assumption, it is obvious that we propose an indicator of this field: the number and ratio of individual, deviant, problematic cases compared to all the cases.

The use of SETE is obvious and unavoidable since the student's evaluation cannot completely be substituted with indirect calculations. Although we criticized the use of SETE earlier, our main argument is that using only SETE (and nothing else) will end up in distorted results and conclusions when measuring knowledge transfer efficiency. As mentioned, indices are necessary as completing SETE as well. Based on this, we propose using the following:

1. The clarity of the teaching material, provided that it is independent from the subject itself to some extent; with the proper teaching method, even difficult issues can be made clear:

a. the standard deviation of the groups' achievements compared to the average standard deviation of teaching,

b. how frequently course elements and explanatory materials are visited/reused,

c. the frequency of questions (FAQ, the use of supplementary, interpretive materials).

2. Student satisfaction, which is mentioned by several authors and is needed for utilization due to attention scarcity

a. time of quitting each course or the time of certain lectures planned in a single block (i.e., time spent on studying/full learning time, or rather, its average),

b. average learning fragmentation (i.e., how many times the complete material is viewed by a student), c. average returning time (how much time passes before the student re-enters after exiting).

3. Learnability (regarding content and quantity)

a. the ratio of students successfully passing the course compared to similar key figures of other (attendance-based) courses,

b. time spent in the system (provided that the session is interrupted in the case of inactivity).

4. The goodness of examinations (availability, conformity, evaluation, etc.)

a. the ratio of good answers to questions compared to the whole,

b. the standard deviation of the time spent on questions,

c. the representativeness of exam questions compared to the complete material (even distribution of questions).

In the case of SETE, a question arises regarding the extent that students can separate how interesting, useful, or compulsory a given course is from other evaluation criteria. In the case of the above key figures that are independent of SETE, there are no misleading connections when calculating differences and standard deviations. We hypothesize that the standard deviation will be low in the case of good learning methods.

The key message is that the key figures based on the deviation from the standard distribution correlate with achievements and efficiency of the teaching system. Thus, the e-learning process parameters listed above provide the possibility of simple and reliable evaluation that gives feedback for future course planning and development.

\section{Validation plans}

As a next step, we intend to validate our proposed method. To do so, we have already approached three large online e-learning content providers (Massive Open Online Courses, a.k.a. MOOC, including but not limited to Coursera with 33 Million learners ${ }^{2}$, Udemy with 80,000+ online courses ${ }^{3}$ ) asking for help in gathering the necessary data. As these courses are taken by a very diverse and huge number of learners, and also most importantly by free will, we consider them appropriate data sources to validate our concept with.

These MOOCs are offering online e-learning courses containing mostly videos, some complementary text-based knowledge, related articles and evaluation questions. The students also have the opportunity to take notes during the videos, or ask from the teachers at any given time. Some courses, or a series of courses can grant an official degree after a successful completion, which gives proper motivation for the students.

When we approached these online content providers, we asked for data according to the students' exams (results, time spent on questions etc.), their statistical behavior during learning (number of course access, time spent on course, average returning time etc.), and also their subjec- 
tive ratings on the course. We asked the content providers for the data to be extracted and sent to us anonymously, so the students could not be identified.

After collecting the data explained above, we intend to perform the calculations detailed in the "Specific indices" section, and compare the results between the courses, the results of the students and also with the student ratings on the courses. Among others, we will examine the distributions of the samples, and plan to do several correlation tests. Also, we are planning to carry out measures of goodness of fit.

After performing all the tests above on all the courses we gather the data from, we hope to come to the conclusion that our concept on measuring the efficiency of e-learning courses are valid and ready to further use and improvement.

\section{Conclusions and outlook}

We have faced several dilemmas, and one of the most important issues is whether we should meet special customer satisfaction at all. Obviously, we should to an extent, but we have to differentiate between certain types of education. There is compulsory and facultative learning. In the first case (like in public education or obligatory corporate training, etc.), customer satisfaction occurs on a higher level (at the society or company level; e.g. in $\mathrm{KPIs}^{4}$ ), while in the latter case, it occurs directly at the student level. However, a proper measurement system seems to be essential in any educational process. Our proposed method aims to satisfy this principle. A measurement method based on the standard distribution of automatically recorded educational system results (and not appraisals directly from the students) adds new opportunities to evaluate the e-learning process.

Further research could collect and analyze several samples to test the proposed evaluation method and key figures in this paper can be tested. By proving the independence of the measurement system, we intend to perform the test reasonably on e-learning solutions used in public education and the corporate sector. The results of future research may prove to be useful and challenge the idea that e-learning can deliver knowledge that is more efficient than traditional courses in classrooms. If the bell curves show a left-skewed distribution (negative skewness), e-learning education would prove to be efficient.

\section{References}

Ballou, D. - Sanders, W. - Wright, P. (2004): Controlling for student background in value-added assessment of teachers. Journal of Educational and Behavioral Statistics, 29(1), p. 37-65. (DOI: 10.3102/10769986029001037)

Berk, R. A. (2005): Survey of 12 strategies to measure teaching efficiency. International Journal of Teaching and Learning in Higher Education, 17(1), p. 48-62.
Callister, R. R. - Love, M. S. (2016): A Comparison of learning outcomes in skills-based courses: online versus face-to-face formats. Decision Sciences Journal of Innovative Education, 14(2), p. 243-256.

Coleman, J. S. - Campbell, E. - Hobson, C. - McParttland, J. - Mood, A. - Weinfield, F. - York, R. (1966): Equality of Educational Opportunity. Washington, DC: US Government Printing Office

Creemers, B. P. - Kyriakides, L. (2006): Critical analysis of the current approaches to modelling educational efficiency: The importance of establishing a dynamic model. School Efficiency and School Improvement, 17(3), p. 347-366. (DOI: 10.1080/09243450600697242)

Cummings, J. L. - Teng, B. S. (2003): Transferring R\&D knowledge: the key factors affecting knowledge transfer success. Journal of Engineering and technology management, 20(1-2), p. 39-68. (DOI: 10.1016/S0923-4748(03)00004-3)

DeLone, W. H. - McLean, E. R. (1992): Information systems success: The quest for the dependent variable. Information Systems Research, 3(1), p. 60-86.

Emery, C. R. - Kramer, T. R. - Tian, R. G. (2003): Return to academic standards: A critique of student evaluations of teaching efficiency. Quality Assurance in Education, 11(1), p. 37-46. (DOI: 10.1108/09684880310462074)

Eom, S. B. - Ashill, N. (2016): The determinants of students' perceived learning outcomes and satisfaction in university online education: An update. Decision Sciences Journal of Innovative Education, 14(2), p. 185-215.

Eom, S. B. - Wen, H. J. - Ashill, N. (2006): The determinants of students' perceived learning outcomes and satisfaction in university online education: An empirical investigation. Decision Sciences Journal of Innovative Education, 4(2), p. 215-235.

Galbraith, C. S. - Merrill, G. B. - Kline, D. M. (2012): Are student evaluations of teaching efficiency valid for measuring student learning outcomes in business related classes? A neural network and Bayesian analysis. Research in Higher Education, 53(3), p. 353374. (DOI: 10.1007/s11162-011-9229-0)

Guri-Rosenblit, S. - Gros, B. (2011): E-learning: Confusing terminology, research gaps and inherent challenges. International Journal of E-Learning \& Distance Education, 25(1)

Guskey, T. R. (2011): Grading reform. Educational Leadership, (2011), p. 17-21.

Hanushek, E. A. - Luque, J. A. (2003): Efficiency and equity in schools around the world. Economics of Education Review, 22(5), p. 481-502.

Heyneman, S. P. (2005): Student background and student achievement: What is the right question? American Journal of Education, 112(1), p. 1-9. (DOI: 10.1086/444512)

Holsapple, C. W. - Lee-Post, A. (2006): Defining, assessing, and promoting e-learning success: An 
information systems perspective. Decision Sciences Journal of Innovative Education, 4(1), p. 67-85.

Jencks, C. - Smith, M. S. - Ackland, H. - Bane, M. J. Cohen, D. - Grintlis, H. - Heynes, B. Michelson, S. (1972): Inequality. New York: Basic Books

Kronholz, J. (2012): Can Khan move the bell curve to the right? Education Next, 12.2.

Li, N. - Marsh, V. - Rienties, B. (2016): Modelling and managing learner satisfaction: Use of learner feedback to enhance blended and online learning experience. Decision Sciences Journal of Innovative Education, 14(2), p. 216-242. (DOI: 10.1080/02602938.2016.1176989)

Larrick, R. P. - Soll, J. B. (2008): The MPG illusion. Science, 320, p. 1593-1594. (DOI: 10.1126/ science.320.5883.1659b)

Nelson, G. S. (2018): The Analytics Lifecycle Toolkit: A Practical Guide for an Effective Analytics Capability. Chichester: John Wiley \& Sons

Nesterowicz, K. - Neacsu, A. - Fereshtehnejad, S. M. - Nemeslaki, A. (2016): Exploring the acceptance of e-learning in continuing pharmacy education. Pharmacy Education, 16.

Sangrà, A. - Vlachopoulos, D. - Cabrera, N. (2012): Building an inclusive definition of e-learning: An approach to the conceptual framework. The International Review of Research in Open and Distributed Learning, 13(2), p. 145-159.

Sampson S. E. (2001): Understanding Service Businesses. Chichester: John Wiley \& Sons Inc.
Sampson S. E. - Froehle, C. M. (2006): Foundations and Implications of a Proposed Unified Services Theory. Production and Operations Management, 15(2), p. 329-343.

Seang, G. S. (2003): Best Practices in KPI. National Conference of Key Performance Indicators 2003 21st - 23rd October 2003 Pan Pacific Hotel, Kuala Lumpur, accessed July 11, 2017, available at http://dominoapp.npc.org.my/publications. nsf/0/4CEC8E267211881B48256DC7002C719F/\$file/ BPKPI221003.pdf

Strother, J. B. (2002): An assessment of the efficiency of e-learning in corporate training programs. The International Review of Research in Open and Distributed Learning, 3(1)

Tyler, L. (2010): Measuring teaching efficiency. Education Week, 29(19), 18.

Vilaseca, J. - Castillo, D. (2008): Economic efficiency of e-learning in higher education: An industrial approach. Intangible Capital, 4(3). (DOI: 10.3926/ ic.2008.v4n3.p191-211)

Wild, R. H. - Griggs, K. A. - Downing, T. (2002): A framework for e-learning as a tool for knowledge management. Industrial Management \& Data Systems, 102(7), p. 371-380. (DOI: $10.1108 / 02635570210439463)$

Woessmann, L. (2004): How Equal are Educational Opportunities? Familiy Background and Student Achievement in Europe and the US. CESifo. 